\title{
Methodology for the LCC-Analysis and the optimal migration of the railway operations control on the example of ETCS
}

\author{
M. Obrenovic, B. Jaeger \& K. Lemmer \\ German Aerospace Center, Institute of Transportation Systems, \\ Braunschweig, Germany
}

\begin{abstract}
In order to reduce the number of approximately 20 different train control systems in Europe, and thus to realise cost effective and seamless cross-border railway operation, The European Train Control System (ETCS) will be implemented within the next years. Besides the given legislative preconditions, the cost efficiency as well as the optimal migration strategy, both on an operative and strategic level, will be crucial for the commercial success of the system.

The Life-Cycle Cost Analysis (LCC) takes into account the overall costs appearing during the entire life cycle, considering all purchasing, owning and the disposal of the system. Additionally it identifies cost drivers by analysing the "cause-and-effect chain" between relevant figures and processes. Therefore, a system breakdown structure plan and a cost breakdown structure plan are mapped on the different phases in the life-cycle of the analysed operations control system. Furthermore, a process analysis needs to be carried out in order to identify and to optimise those areas where cost-drivers are generated, e.g. the development or the maintenance process. Based on the LCC Analysis and additionally on a Multi-Criteria Analysis, considering operational, technical and other aspects, the optimal target state will be identified.

In a last step, migration scenarios for the selected system need to be developed and evaluated systematically. Thus, the optimal migration strategy can be carried out. Furthermore, the migration costs and the duration of the process have to be considered beforehand in the LCC Analysis. As a result, a closed loop and an interaction related to both thematic areas - LCC and the migration of the railway operations control - are found.

The Institute of Transportation Systems has developed a consistent methodological framework including tool-support, which is covering this process and will be demonstrated on ETCS in this contribution.
\end{abstract}

Keywords: migration, Life Cycle Costing, ETCS. 


\section{Introduction}

The migration of innovative technologies into the complex railway system is characterised by a number of heterogeneous criteria and constraints. Due to the shared functionalities and components allocated on the track-side as well as the rolling stock, particularly the railway operations control raises high requirements on the process. Mayor goals of the ETCS migration are e.g. a certain level of operational and RAMS (Reliability, Availability, Maintainability, Safety) performance as well as low LCC and migration costs whilst providing technical and operational interoperability. Additionally, train circulation on European corridors and the mix between passenger and freight traffic are to be considered. Thereby, a multi-dimensional optimisation problem has to be solved. This requires a tool-supported methodology dealing with the migration in the domain of railway systems. [2] Figure 1 shows the process model based on the migration drive to change the current system, the selection of the appropriate target state as well as the development and evaluation of migration strategies.

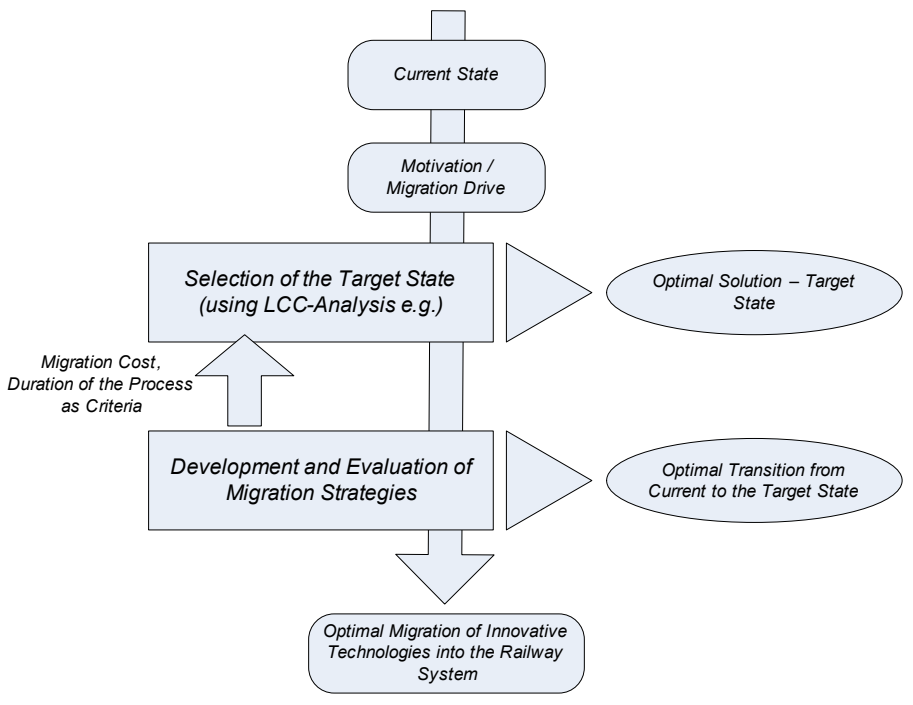

Figure 1: Interaction in the process model for the migration of new technologies.

Expecting the LCC to be one of crucial criteria for system selection, and bearing in mind that migration cost and duration are to be considered with the LCC-Analysis already, the closed loop and the interaction between the selection of the target state and the migration in the overall process model become evident. 


\section{European Train Control System - a new technology for European railways}

Currently approximately 20 different train control systems are in use in Europe. In order to reduce this number, and thus to realise cost effective and seamless cross-border railway operation, ETCS will be implemented within the next years. Therefore, the legislative preconditions in the form of EU directives 96/48/EG and 2001/16/EG have been established. Besides the political demand, the economical efficiency and the optimal migration of this new technology will be crucial conditions for its success. The migration on the strategic level is described by corridors for the high-speed and conventional rail. Now each country has to find the optimal way for the migration of ETCS on particular corridors, concerning the characteristics of the national railway network as well as the rest of the related corridor and the entire future ETCS network.

Deploying ETCS on the European railway network, among others, the following impacts are expected:

- Decrease of transport time, especially in the cross-boarder traffic;

- Increase of track capacities;

- Increase and harmonisation of the safety level of European railways;

- Lower LCC especially due to

- Lower asset cost due to the changing of the purchasing market, standardisation and harmonisation;

- Less equipment, and thus lower maintenance cost track-side;

- Interoperability;

- $\quad$ Opening of the sales markets for the suppliers;

- Barrier-free access to the railway infrastructure.

But on the other hand, high invest for the ETCS migration will be necessary. The problem of national legacy systems and their long life-cycle and thus long term depreciation has to be solved. Financing of the ETCS equipment and certification partially by subsidies for the Infrastructure Managers (IM) and Train Operator Companies (TOC) is necessary. All these questions, as well as the identification of the suitable ETCS Level for certain track sections, have to be answered on order to ensure the commercial success of the system.

\section{LCC-analysis as a methodology for the system selection}

For the identification of the criteria suitable for the selection of the target system, the specific migration drive has to be regarded, i.e. the motivation to introduce a new technological system into an existing technical environment. There are four basic types of motivation, which can be identified for the migration of railway operations control [2]:

- Rationalisation;

- Advancement of the track performance (e.g. interoperability, speed);

- Absence of the availability of technical components or systems;

- Political decisions. 
Due to the high complexity of the decision model, including figures and indicators from the economical, technical, operational or political point of view, the Value Benefit Analysis (VBA) is a suitable method to be applied. It is an approach for the systematic operations research, used at problems of the selection by different project options. The VBA originates from the engineering sciences and allows, contrary to the Cost-Benefit Analysis, the view on nonmonetary assessment criteria as well, and aims not only at the economic efficiency. Nevertheless, the economical aspects and especially the LCC of the regarded systems will be crucial criteria in the decision process, receiving the appropriate weight within the scope of the VBA.

The LCC-Analysis takes into account the overall costs appearing during the entire life cycle, considering all purchasing, owning and the disposal of the system. It additionally identifies cost drivers by analysing the "cause-and-effect chain" between relevant figures and processes. Therefore, a LCC-Model is to be elaborated for the regarded operations control system. Furthermore, there is a process analysis to be done in order to identify and optimise the areas where the cost-drivers are generated, e.g. the development or the maintenance process. The Standard DIN EN 60300-3-3 [3] gives a guideline including the elaboration of the system breakdown structure plan as well as the cost breakdown structure plan, needed for the analysis.

LCC-Model is a simplified image of the reality, which abstracts the main characteristics and attributes of the regarded system transferring them into the cost factors. Especially due to the long life-cycle of the railway operations control, these costs have to be estimated partially. The long life-cycle requires the consideration of the product modification costs during the operation phase, too. In the next sections, both the system breakdown structure plan as well as the cost breakdown structure plan for ETCS will be elaborated.

\subsection{System breakdown structure plan for ETCS}

In order to develop the LCC-Model, the system analysis has to be carried out first. Thereby, the system breakdown structure shows the system components, i.e. units the LCC can be allocated to. Thus, the first step for the identification of cost drivers is done. Separated in three parts

- Track-side components;

- GSM-R;

- On-board components;

Fig. 2 shows the system structure of ETCS. Thereby, we renounce a more detailed view - this level seams sufficient in order to present the methodology.

$\begin{array}{ll}\text { LEU } & \text { Lineside Electronic Unit } \\ \text { RBC } & \text { Radio Block Center } \\ \text { GSM-R } & \text { Global System for Mobile Communication - Railway } \\ \text { OBU } & \text { On-board Unit }\end{array}$


EVC European Vital Computer

JRU Juridical Recording Unit

TIU Train Interface Unit

BTM Balise Transmission Module

RTM Radio Transmission Module

LTM Loop Transmission Module

STM Specific Transmission Module / Translation of the National System

MMI Man-Machine Interface / Driver-Machine Interface

Once the system is analysed, the possible cost positions, arising during the life-cycle of the regarded CC-System (Control-Command), are to be identified. Therefore, in the following section a cost structure will be elaborated. Thus, single cost positions occurring during the life-time can be mapped on the system components.



Figure 2: $\quad$ System breakdown structure of ETCS.

\subsection{Cost breakdown structure plan}

From the user point of view - Infrastructure Mangers and Train Operator Companies - three basic phases, specifying the LCC, can be identified (Fig. 3). 


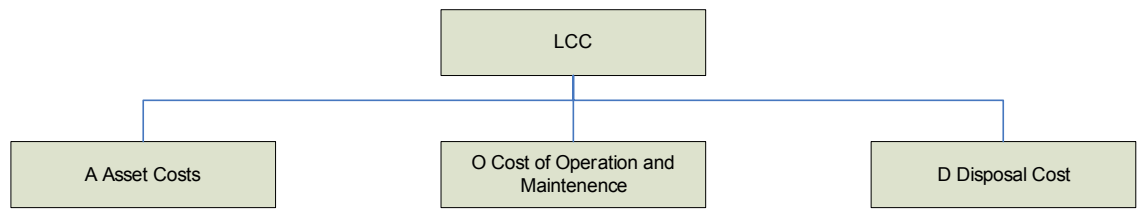

Figure 3: Layer of the LCC breakdown structure - operator's point of view.

In this contribution, the design and the development of the system won't be regarded. For system users, these costs will be expressed in the purchase price and the usage of the system during the operation. Nevertheless, these phases are crucial for the determination of the LCC. Thus, it is highly recommended to optimise the development process, bearing in mind that approx. $3 / 4$ of the LCC are being determined there.

In the next sections, costs appearing during the three phases of the user-oriented life-cycle will be presented.

\subsubsection{Asset cost $-\mathbf{A}$}

The classical investment appraisal uses asset costs as a key criterion for the system selection. In the LCC-Analysis, it is only one part of the chain. Fig. 4 shows the elements of the asset costs.

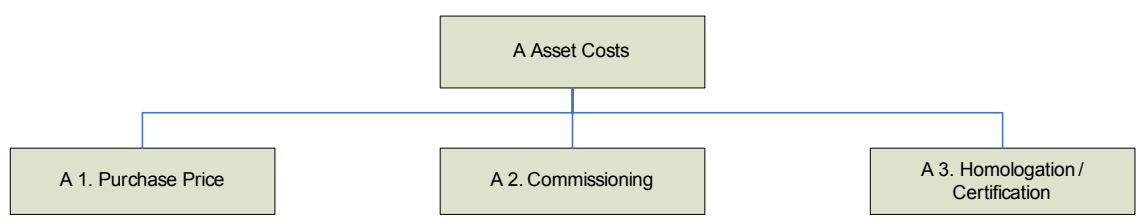

Figure 4: $\quad$ Layer of the asset cost breakdown structure.

Table 1: $\quad$ Asset costs.

\begin{tabular}{|l|l|}
\hline A 1 & Purchase Price \\
\hline A 2.1 & Opportunity Costs of Commissioning - Downtime, etc. \\
\hline A 2.2.1 & Personnel Training Costs for Commissioning \\
\hline A 2.2.2 & Personnel Installation Costs of Commissioning \\
\hline A 2.3.1 & Material Costs of Commissioning - Supplies \\
\hline A 2.3.2 & Material Costs of Commissioning - Facilities \\
\hline A 2.4 & Planning / Programming Costs of Commissioning \\
\hline A 3 & Homologation / Certification \\
\hline
\end{tabular}

\subsubsection{Cost of operation and maintenance - $O$}

Especially during the long-term operation phase, various costs can be identified (Fig. 5, Table 2). 


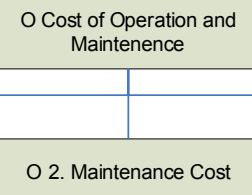

Figure 5: Layer of the cost of operation and maintenance breakdown structure.

Table 2: $\quad$ Cost of operation and maintenance.

\begin{tabular}{|l|l|}
\hline O 1.1 .1 & Material Cost of Operation - Supplies \\
\hline O 1.1 .2 & Material Cost of Operation - Facilities \\
\hline O 1.2 & Personnel Cost of Operation \\
\hline O 1.3 & Occupancy Cost of Operation \\
\hline O 2.1.1 & Personnel Cost of Preventive Maintenance \\
\hline O 2.1.2 & Costs for Spare Parts of Preventive Maintenance \\
\hline O 2.1.3 & Tool Costs of Preventive Maintenance \\
\hline O 2.2.1 & Personnel Cost of Repair \\
\hline O 2.2.2 & Costs for Spare Parts of Repair \\
\hline O 2.2.3 & Tool Costs of Repair \\
\hline O 2.3 & Opportunity Cost for Downtime \\
\hline O 3.1 & Cost of Capital \\
\hline O 3.2 & Cost of System Modification \\
\hline
\end{tabular}

Due to the strong impact on the entire LCC, in this phase the processes determining the cost indicators and figures are to be analysed in-depth. Thereby, the impact of key figures like Mean Time Between Maintenance (MTBM), Mean Time To Repair (MTTR) or Mean Time To Failure (MTTF) has to be regarded. Modelling of the influence of the railway operation or the internal processes on these figures allows the identification of possible cost drivers and thus the identification of optimisation areas.

\subsubsection{Disposal cost - D}

In spite of the extremely long life-time of railway operations control, the costs related to the recycling are to be considered, too (Fig. 6).

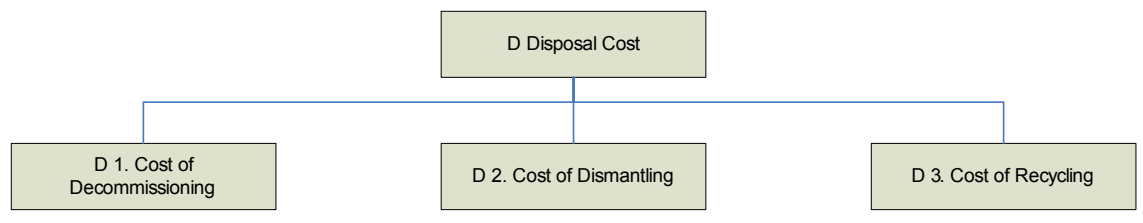

Figure 6: Layer of the disposal cost breakdown structure. 
Table 3: Disposal cost.

\begin{tabular}{|l|l|}
\hline D 1.1 & Personnel Cost of Decommissioning \\
\hline D 2.1 & Personnel Cost of Dismantling \\
\hline D 2.2 1 & Material Cost of Dismantling - Supplies \\
\hline D 2.2.2 & Material Cost of Dismantling - Facilities \\
\hline D 3 & Cost of Recycling \\
\hline
\end{tabular}

\subsubsection{Overall LCC}

In order to determine the overall LCC, the single cost positions presented in the sections above have to be accumulated.

$$
L C C=A_{0}+\sum_{j=1}^{n}\left(O_{j} \times \frac{1}{(1+d)^{j}}\right)+D_{n}
$$

LCC Life Cycle Costs (User-Oriented)

$\mathrm{A}_{0} \quad$ Positions of Asset Cost to the Date 0

$\mathrm{O}_{\mathrm{j}} \quad$ Positions of Cost of Operation and Maintenance during the Life-Cycle

$\mathrm{D}_{\mathrm{n}} \quad$ Positions of Disposal Cost to the Date $n$

j...n Life-Time of the System

d Discount Rate

To consider the net-present-value, the costs are to be discounted to a defined rate. Using this approach, an efficient method for the assessment of economical aspects in the selection process can be applied.

\section{Development and assessment of migration scenarios}

Once the appropriate system is selected, an optimal strategy for the migration from the current state into the target state has to be elaborated. Here, the transition from various national CC-Systems toward ETCS is meant.

Especially due to the safety relevant interaction of the track-side and the onboard system components of the railway operations control, the development of migration scenarios is a complex process. The crucial requirement is to keep up operation during the migration period. Considering the fact that ETCS is not compatible to the national CC-Systems, which have to be replaced, parallel equipment for a certain period is necessary.

The final target of the ETCS migration is not to have one more train control system overlaid to the national systems. Rather, ETCS has to be established as a substitution of national CC-Systems, at least on defined corridors. This should be a requirement on the migration process, while having in mind the higher operational and maintenance costs (as parts of LCC) in case of the parallel equipment track- or train-side.

ETCS migration raises problems on different levels. On the one hand, we have a strategic question of ETCS deployment using the corridor strategy. On the 
other hand, the characteristics of certain tracks and sections have to be considered on the operative level. Assessment of different migration strategies, e.g.:

- $\quad$ Parallel equipment with ETCS and the national CC-System track-side;

- Parallel equipment on-board;

- Parallel equipment on both system sides;

- $\quad$ STM-Strategy;

includes the analysis and optimisation of two crucial figures: cost and time.

Based on the published data on the one hand and some assumptions being necessary due to the low maturity of the system on the other hand, Fig. 7 shows one of the possible ETCS Level 1 strategies. It is the parallel equipment trainside, including the system deployment (infrastructure and rolling stock) and the annual cost trend. Thus, the identification of the "break-even-date", realising annual (not general) benefits of the ETCS migration, can be determined. See detailed calculation in [1].
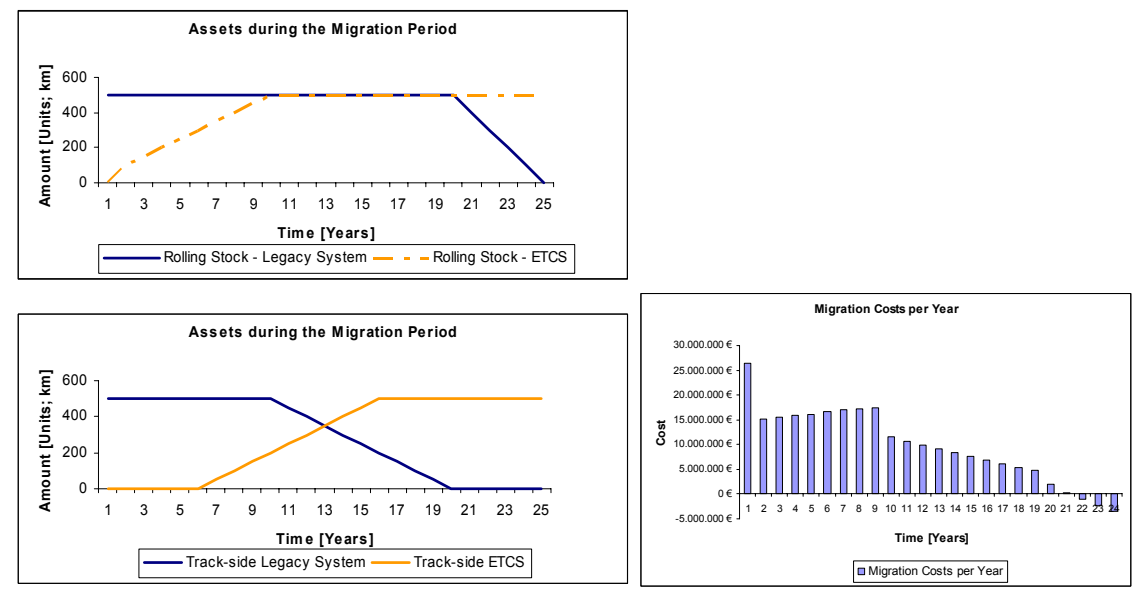

Figure 7: Example: parallel equipment train-side - assets and annual cost trend [1].

Migration cost in each scenario is calculated by comparing the asset costs and the cost of operation and maintenance of ETCS with the cost of the reference scenario, keeping the legacy system [4].

As a part of the methodology, at the Institute of Transportation System of the German Aerospace Center, a tool-support for the evaluation of migration scenarios is provided as well.

Migration cost has to be considered already in the LCC-Analysis, carried out in the selection phase. Due to the recursive dependence of both phases selection and migration - there is a closed loop regarding the general methodology. Normally, having a small number of alternatives in the domain of railway operations control and especially CC-Systems, the solution space and thus the global problem is manageable. 


\section{Conclusions}

Economical efficiency and the optimal migration of innovative technologies in the railway domain are key conditions for their success. Currently, in spite of the political pressure, the pace of deployment of the new European Train Control System will significantly depend on these aspects. Therefore, a methodical determination of impacts on the one hand and the optimisation on the other will be necessary to convince the IMs and TOCs of the system. To make the decision on the implementation at all, respectively on the appropriate ETCS level on certain track sections, LCC-Appraisal should be applied within the scope of the Value-Benefit-Analysis. Thereby, the elaboration of the system breakdown structure and the cost breakdown structure is the basis for the LCC-Model. From the users' point of view, costs of purchasing, owning as well as the disposal of the system have to be considered. Thus, single cost positions during the life-time and the cost drivers can be identified. Based on this information on the one hand and by comparing the alternatives, a selection of the optimal system solution can be made. On the other hand, the optimisation areas become evident.

Solving the optimisation problem, occurring with respect to the migration of railway operations control, deployment of ETCS will be accelerated. To minimise additional cost and operational constraints, a methodical approach has to be applied in the process of the development and evaluation of migration strategies. Furthermore, both the strategic as well as the operative level of the migration on the one side and the claims of IMs as well as TOCs on the other side have to be considered.

From the economical point of view, there is a closed loop between the LCC-Analysis and the optimal migration. Integration of both aspects in a consistent methodology, as shown in this contribution, ensures a suitable approach, covering the questions of economical efficiency and the migration of railway operations control.

\section{References}

[1] Obrenovic, M., Jaeger, B., Lemmer, K., Development and Evaluation of Migration Strategies for ETCS Level 1 Applied on a Synthetic Track, ZEL 2006, Zilina (SK) - accepted

[2] Knollmann, V., Obrenovic, M., Jaeger, B., Lemmer, K., Optimized Migration Process in Rail Traffic Using Simulation Support, $1^{\text {st }}$ International Seminar on Railway Operations Modelling and Analysis, RailDelft2005, Delft (NL)

[3] DIN EN 60300-3-3 Dependability management - Part 3-3: Application guide - Life cycle costing (IEC 60300-3-3:2004); German version EN 60300-3-3:2004

[4] Obrenovic, M., Meyer zu Hoerste, M., Jaeger, B., Phase Model for the Development and Evaluation of Migration Strategies in Rail Traffic, The $5^{\text {th }}$ European Congress and Exhibition on Intelligent Transport Systems and Services (HITS), Hannover 2005 